\title{
$\gamma$-Secretase-Dependent Proteolysis of Transmembrane Domain of Amyloid Precursor Protein: Successive Tri- and Tetrapeptide Release in Amyloid $\beta$-Protein Production
}

\author{
Mako Takami ${ }^{1,2}$ and Satoru Funamoto ${ }^{1}$ \\ ${ }^{1}$ Department of Neuropathology, Graduate School of Life and Medical Sciences, Doshisha University, Kyotanabe, \\ Kyoto 610-0934, Japan \\ ${ }^{2}$ Pharma Eight Co. Ltd., Kyoto, Kyoto 602-0841, Japan \\ Correspondence should be addressed to Satoru Funamoto, sfunamot@mail.doshisha.ac.jp
}

Received 13 September 2012; Revised 27 November 2012; Accepted 12 December 2012

Academic Editor: Jeremy Toyn

Copyright (C) 2012 M. Takami and S. Funamoto. This is an open access article distributed under the Creative Commons Attribution License, which permits unrestricted use, distribution, and reproduction in any medium, provided the original work is properly cited.

\begin{abstract}
$\gamma$-Secretase cleaves the carboxyl-terminal fragment ( $\beta$ CTF) of APP not only in the middle of the transmembrane domain $(\gamma$ cleavage), but also at sites close to the membrane/cytoplasm boundary ( $\varepsilon$-cleavage), to produce the amyloid $\beta$ protein $(\mathrm{A} \beta)$ and the APP intracellular domain (AICD), respectively. The AICD49-99 and AICD50-99 species were identified as counterparts of the long $A \beta$ species $A \beta 48$ and $A \beta 49$, respectively. We found that $A \beta 40$ and AICD50-99 were the predominant species in cells expressing wild-type APP and presenilin, whereas the production of A $\beta 42$ and AICD49-99 was enhanced in cells expressing familial Alzheimer's disease mutants of APP and presenilin. These long A $\beta$ species were identified in cell lysates and mouse brain extracts, which suggests that $\varepsilon$-cleavage is the first cleavage of $\beta$ CTF to produce A $\beta$ by $\gamma$-secretase. Here, we review the progress of research on the mechanism underlying the proteolysis of the APP transmembrane domain based on tri- and tetrapeptide release.
\end{abstract}

\section{Introduction}

The amyloid precursor protein (APP) is a type I membrane protein. After ectodomain shedding by $\beta$-secretase, the carboxyl-terminal fragment ( $\beta \mathrm{CTF}$ ) of APP becomes a direct substrate of $\gamma$-secretase and is processed into the amyloid $\beta$ protein $(\mathrm{A} \beta)$ and the APP intracellular domain (AICD) [1-5]. $\gamma$-secretase is an enigmatic protease composed of presenilin 1/2, nicastrin, Aph-1, and Pen-2 that catalyzes proteolysis in the hydrophobic environment of the lipid bilayer [6-15]. Currently, over 50 molecules are reported as $\gamma$-secretase substrates, which reflects the physiological importance of this enzyme [16]. For instance, the Notch receptor on the plasma membrane is cleaved by $\gamma$-secretase upon ligand binding and the liberated Notch intracellular domain (NICD) translocates into the nucleus and activates the expression of transcription factors to suppress neuronal differentiation $[17,18]$. This indicates that inhibition of $\gamma$-secretase for suppression of $\mathrm{A} \beta$ production causes harmful side effects. To avoid this risk in anti-Alzheimer's disease $(\mathrm{AD})$ therapeutics, it is very important to elucidate the molecular mechanism underlying $\gamma$-secretase-dependent proteolysis. Recently, it was revealed that $\gamma$-secretase forms a hydrophilic pore and three water-accessible cavities [19-23]. Here, we review the progress of research on the mechanism underlying the proteolysis of the transmembrane domain of $\beta$ CTF.

\section{Discovery of $\varepsilon$-Cleavage during APP Processing}

After the $\beta$-secretase-dependent cleavage of APP, the ectodomain of APP is released into the extracellular space and $\beta$ CTF (as a stub in the lipid bilayer) is the direct substrate of $\gamma$-secretase $[2,3,24]$. $\beta$ CTF is composed of 99 amino acids and is eventually processed into the $38-43$-residue-long $A \beta$, suggesting that the counterparts of those $A \beta$ species should 


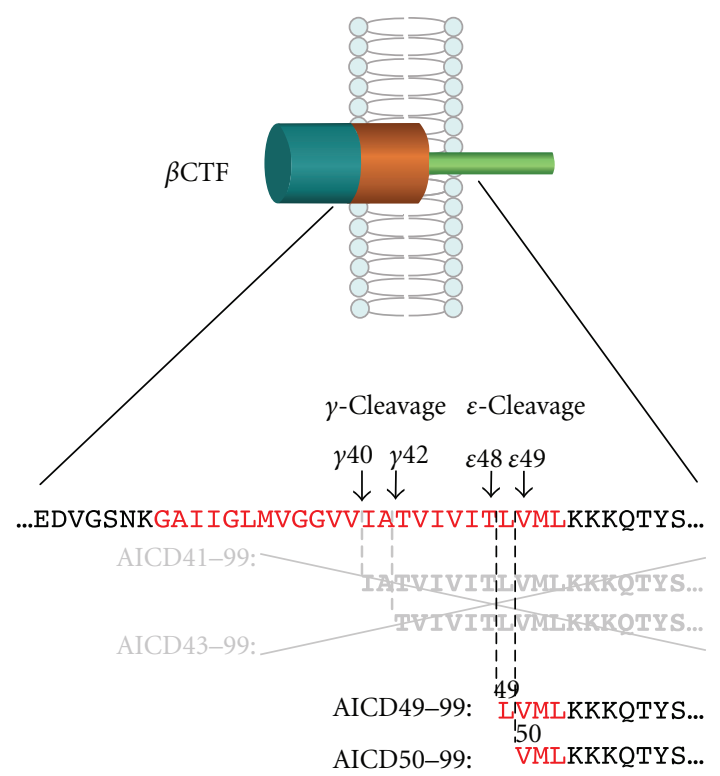

mNotch-1

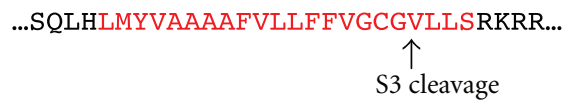

FIGURE 1: $\beta$ CTF is cleaved at the membrane-cytoplasm boundary and not in the middle of the transmembrane domain ( $\varepsilon$-cleavage), to release the AICD49-99 and AICD50-99 species. The production of AICD species was inhibited in the presence of a $\gamma$-secretase inhibitor. $\mathcal{E}$-Cleavage is analogous to the $\mathrm{S} 3$ cleavage of mNotch-1. Red indicates the transmembrane domain.

contain 56-61 residues [4, 25-29]. However, 50-51-residuelong AICDs were identified that correspond to residues 49-99 and 50-99 of $\beta$ CTF (AICD49-99 and AICD5099), instead of 56-61-residue-long species (Figure 1) [3032]. These AICD species were suppressed by L-685,458, a transition state analogue $\gamma$-secretase inhibitor, and by expression of a dominant-negative mutant of presenilin (PS), suggesting that $\gamma$-secretase cleaves $\beta$ CTF not only in the middle of the transmembrane domain ( $\gamma$-cleavage), but also at sites close to the membrane/cytoplasm boundary ( $\varepsilon$ cleavage), releasing AICD49-99 and AICD50-99. $\varepsilon$-Cleavage sites are analogues of the Notch S3 cleavage site, which is located at the membrane, near the cytoplasm (Figure 1). Cleavages similar to the APP $\varepsilon$-cleavage were identified in other proteins, such as amyloid precursor-like protein 1 (APLP-1), APLP-2, CD44, Delta 1, E-cadherin, ErbB4, and LRP1 [30, 33-37]. It is reasonable to consider that the water molecules required for proteolysis have access to the catalytic center of $\gamma$-secretase from the cytoplasm, rather than from the extracellular space, and that $\varepsilon$-cleavage precedes $\gamma$ cleavage during APP processing.

\section{Relationship between $\boldsymbol{\gamma}$-and $\varepsilon$-Cleavage}

$\mathrm{CHO}$ cells expressing familial $\mathrm{AD}$ (FAD) mutants of PS or APP increase production ratio of $A \beta 42(A \beta 43)$ to $A \beta 40$ compared to cells expressing wild-type PS or APP these longer $A \beta$ species are more hydrophobic and more prone to form neurotoxic aggregates. $\mathrm{CHO}$ cells expressing wildtype PS preferentially release AICD50-99, whereas those expressing a subset of familial AD (FAD) mutants of PS or APP exhibit an increased proportion of AICD49-99 (Figure 2(a)) [42]. As those FAD mutations cause an increase in the $\mathrm{A} \beta 42 / \mathrm{A} \beta 40$ ratio, a potential link between $\gamma$ - and $\varepsilon$-cleavage was assumed. To test this, we expressed $A \beta 49$ and $\mathrm{A} \beta 48$, which are potential counterparts of AICD5099 and AICD49-99, respectively, in CHO cells. The cells expressing $A \beta 49$ predominantly secreted $A \beta 40$, whereas those expressing $A \beta 48$ exhibited a significantly increased proportion of $A \beta 42 / A \beta 40$ (Figure 2(b)) [43]. These data indicate that $\varepsilon$-cleavage sites determine the preference for $\gamma$ and $\varepsilon$-cleavage sites to produce $A \beta 40$ and $A \beta 42$. Long $A \beta$ species, $A \beta 49$ and $A \beta 48$, have been identified in cell lysates and mouse brain extracts, which suggests that $\varepsilon$-cleavage is the first cleavage of $\beta$ CTF to produce $\mathrm{A} \beta$ by $\gamma$-secretase [44]. On the other hand, $\varepsilon$-cleavage can be considered as endopeptidase activity of $\gamma$-secretase. FAD mutations did not consistently impair the endopeptidase activity on APP, Notch, ErbB4, and N-Cadherin, but altered $\gamma$-cleavage of APP, especially fourth cleavage to produce $A \beta 40$ and $A \beta 38$ from $A \beta 43$ and $A \beta 42$, respectively [45]. Such dissociation between $\varepsilon$-cleavage and $\gamma$-cleavage was also proposed by Quintero-Monzon et al. [46]. 

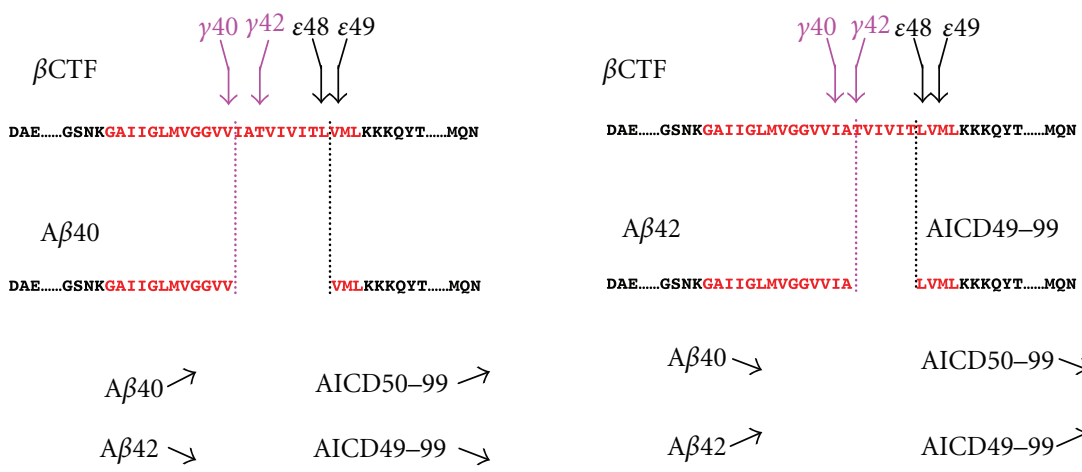

DAE......GSNKGAI I GLMVGGVVIA

AICD50-99 $>$

$\mathrm{A} \beta 40 \longrightarrow$

AICD49-99 $>$

(a)
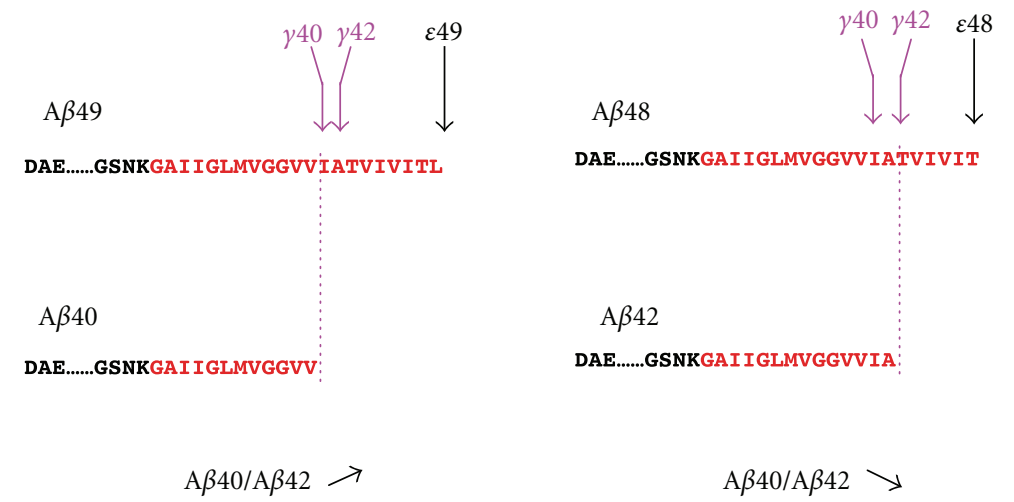

(b)

FIGURE 2: Relationship between $\gamma$ - and $\varepsilon$-cleavage. (a) Cells expressing wild-type PS or APP predominantly produce A $\beta 40$ and AICD50-99, while cells expressing a FAD mutant of PS or APP exhibited increased proportion of A $\beta 42$ and AICD49-99. (b) Expression of A $\beta 49$ results in an increase in $\mathrm{A} \beta 40 / \mathrm{A} \beta 42$ ratio, whereas expression of $\mathrm{A} \beta 48$ leads to opposite results. $\nearrow$ increase, $\backslash$ decrease.

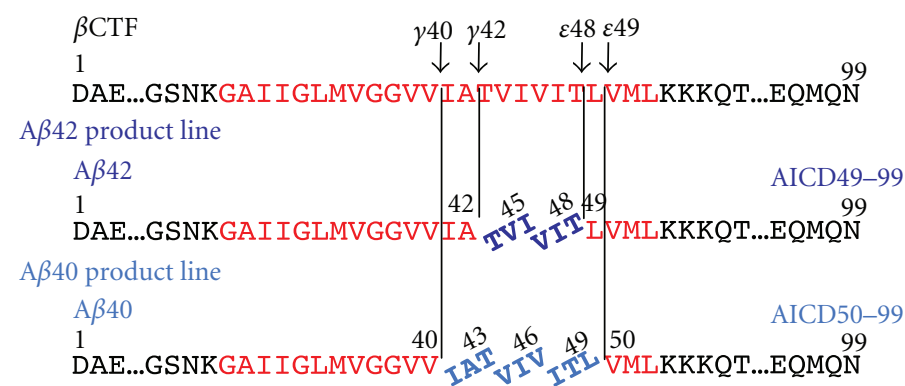

(a)

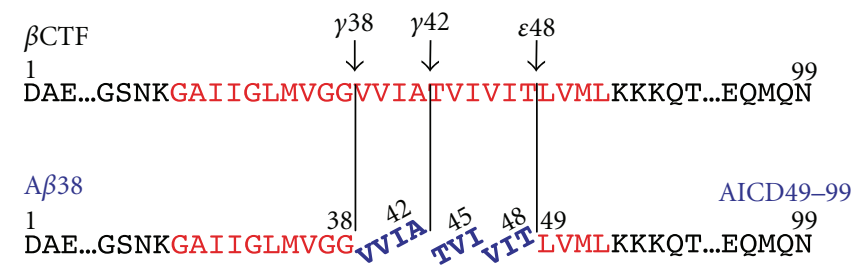

(b)

FIGURE 3: Tri- and tetrapeptide release from $\beta$ CTF. (a) Upon $\varepsilon$-cleavage at $\varepsilon 48, \gamma$-secretase releases the VIT and TVI tripeptides successively to produce $\mathrm{A} \beta 42$. (b) In the $\mathrm{A} \beta 40$ product line, after $\varepsilon$-cleavage at $\varepsilon 49, \beta \mathrm{CTF}$ is converted into $\mathrm{A} \beta 40$ by releasing ITL, VIV, and IAT. A $\beta 42$ is a direct substrate during $\mathrm{A} \beta 38$ production, which acts by releasing the VVIA tetrapeptide. 


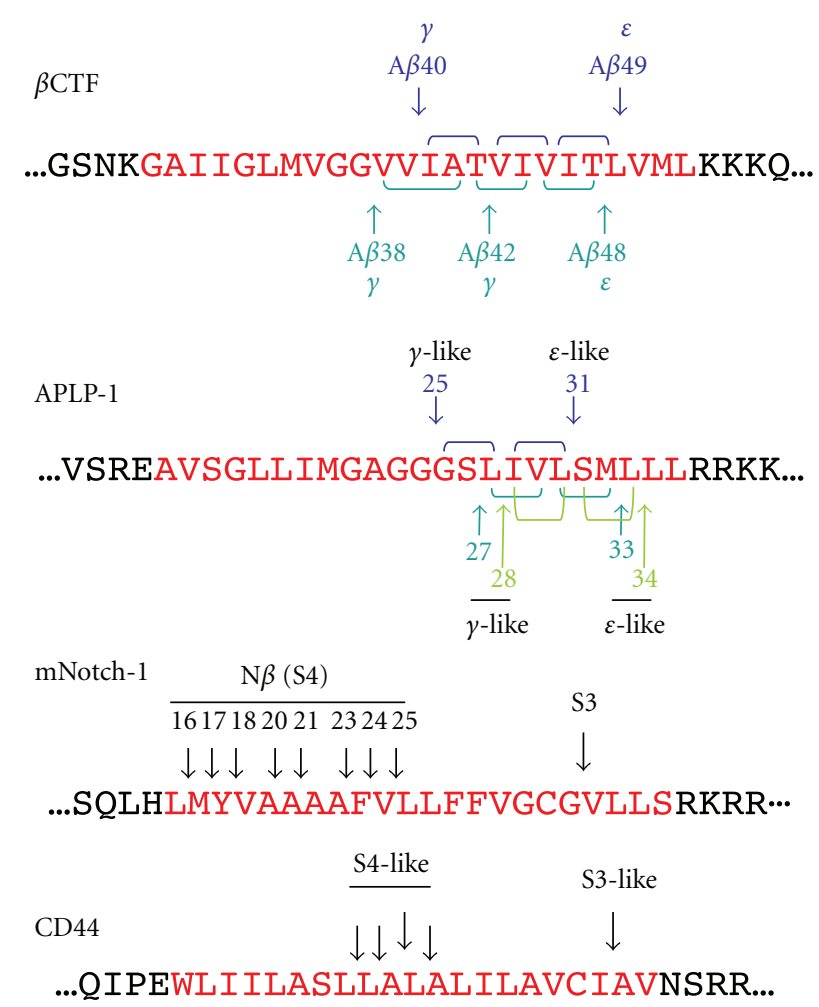

FIGURE 4: Multiple cleavage sites on the transmembrane domain of $\gamma$-secretase substrates. APP [38], APLP-1 [30, 39], mNotch-1 [40], and CD44 [41].

\section{Tripeptide Hypothesis}

Treatment with $\mathrm{N}$-[N-(3,5-difluorophenacetyl)-L-alanyl](S)-phenylglycine t-butyl ester (DAPT), a $\gamma$-secretase inhibitor, suppressed extracellular A $\beta$ in cells expressing APP [47]. The levels of the intracellular $A \beta 40$ and $A \beta 42$ species also decreased after DAPT treatment; however, intracellular $\mathrm{A} \beta 43$ and $\mathrm{A} \beta 46$ increased in a dose-dependent manner [44, $48,49]$. Tryptophan substitutions of $\gamma$-cleavage site (41-43) of APP attenuated $\mathrm{A} \beta$ secretion, but accumulated $\mathrm{A} \beta 45$ species in cell lysate. Tryptophan substitutions of $\varepsilon$-cleavage site (48-52) of APP decreased A $\beta$ production and allowed longer AICD46-99 production. Tryptophan substitutions of $\xi$-cleavage site (45-47) also suppressed A $\beta$ production. These substitution studies also implied successive cleavage of APP for $\mathrm{A} \beta$ production after $\mathcal{\varepsilon}$-cleavage [50].

$\gamma$-Secretase containing mature nicastrin accumulates in lipid rafts, which indicates that active $\gamma$-secretase mainly localizes to the lipid raft of cells [51]. Lipid rafts are an ideal material to investigate $\mathrm{A} \beta$ production in the membrane environment. A $\beta 46$ was the dominant species in a lipid raft isolated from DAPT-treated cells. Interestingly, incubating this lipid raft in the absence of DAPT resulted in production of $A \beta 40$ and $A \beta 43$, but not of $A \beta 42$ [52]. These data suggest that $\mathrm{A} \beta 46$ is mainly converted into $\mathrm{A} \beta 40$ by releasing VIV and IAT tripeptides (successive tripeptide release, tripeptide hypothesis; A $\beta 40$ product line) (Figure $3(\mathrm{a})$ ). On the other hand, $\mathrm{CHO}$ cells expressing an FAD mutant of presenilin 2 exhibited a decrease in intracellular A $\beta 42$ and a concomitant increase in intracellular $\mathrm{A} \beta 45$ levels in the presence of DAPT, suggesting that $A \beta 45$ is a precursor of $A \beta 42$ by releasing TVI (A $\beta 42$ product line) (Figure $3(\mathrm{a})$ ) [53]. It is reasonable to consider that two major product lines lead to $\mathrm{A} \beta 40$ and $\mathrm{A} \beta 42$ production (Figure 3(a)).

\section{Identification of Tri- and Tetrapeptides Released from $\beta \mathrm{CTF}$}

The most effective approach to confirm tripeptide release from $\beta$ CTF is the identification of those tripeptides directly in the reaction mixture of $\mathrm{A} \beta$ production. CHAPSO soluble $\gamma$-secretase was isolated and incubated with the $\beta \mathrm{CTF}$ substrate. LC-MS/MS analysis identified five major tripeptides, and $\gamma$-secretase inhibitors abolished the production of these molecules. ITL, VIV, and IAT were predicted tripeptides in the $\mathrm{A} \beta 40$ product line (Figure 3(a)). The amounts of $\mathrm{A} \beta 40$ and $\mathrm{A} \beta 43$ in the reaction mixture, as assessed using Western blotting, corresponded roughly to the predicted $A \beta 40$ and $A \beta 43$ levels, respectively [38]. VIT and TVI were also detected in the $\mathrm{A} \beta 42$ product line, as predicted (Figure 3(a)). Interestingly, the VVIA tetrapeptide was detected in the reaction mixture only in the absence of $\gamma$ secretase inhibitors (Figure 3(b)). We postulated that VVIA was released from $A \beta 42$ to produce $A \beta 38$. No significant difference was detected between the level of $A \beta 42$ by Western blot quantification and that by LC-MS/MS quantitative estimation. These results indicate that $\gamma$-secretase releases 
tri- and tetrapeptides successively upon $\varepsilon$-cleavage of $\beta \mathrm{CTF}$, to produce $\mathrm{A} \beta$ species. These tri- and tetrapeptides released from $\beta$ CTF were detected even in the lipid raft fraction (Takami, unpublished observation).

\section{Is Tripeptide Release a General Property of Substrate Cleavage by $\gamma$-Secretase?}

Successive tripeptide release was observed in $\beta$ CTF processing by $\gamma$-secretase. We also found that $\gamma$-secretase released triand tetrapeptides successively from $\alpha$ CTF substrate (Takami, unpublished observation). Recently, tripeptide spacing of endoproteolysis on presenilin has been reported [54]. These suggest that successive tri- and tetrapeptide release is a general property of $\gamma$-secretase-mediated intramembrane proteolysis.

Yanagida et al. reported that APLP-1 was also cleaved into three $A \beta$-like peptides [39]. As three $\varepsilon$-like cleavages are known, it is likely that APLP-1 is processed in three product lines by successive tripeptide release [30] (Figure 4). The transmembrane domain of mNotch- 1 is cleaved by $\gamma$-secretase after ectodomain shedding to liberate NICD (S3 cleavage). NICD containing V1744 was found as the prominent species produced by S3 cleavage [55]. To date, it seems reasonable to suppose that there is a single cleavage site in S3. $\gamma$-Secretase also cleaves mNotch-1 at the lumenmembrane boundary (S4 cleavage) to release Notch $\beta$ peptides $(\mathrm{N} \beta)$ (Figure 4$)[40,56,57]$. Fenofibrate treatment increased the proportion of $\mathrm{N} \beta 25$, but not that of $\mathrm{N} \beta 21$, which implies that $\mathrm{N} \beta 25$ and $\mathrm{N} \beta 21$ correspond to $\mathrm{A} \beta 42$ and $\mathrm{A} \beta 40$, respectively [57]. However, it is unlikely that several $\mathrm{N} \beta$ product lines exist in Notch processing because of the single $\mathrm{S} 3$ site. The production of $\mathrm{N} \beta$ species may not fit the tripeptide-processing model (Figure 4). CD44 is cleaved not only at the membrane-cytoplasm boundary, but also at the middle of the transmembrane domain, which results in the release of $A \beta$-like peptides $[33,41]$. Similar to Notch, the processing of the CD44 transmembrane domain may not fit the tripeptide-processing model (Figure 4).

\section{Conclusion and Perspectives}

The tripeptide hypothesis was confirmed in the processing of the APP transmembrane domain, which accounts for the production of $\mathrm{A} \beta$ species. Although the physiological significance of the multiple cleavage of the transmembrane domain is unknown, it is important to illustrate the cleavage mechanisms of other $\gamma$-secretase substrates, because the limitation of this stepwise mechanism would help to elucidate the substrate-specific inhibition of $A \beta$ production. As shown in Figure 4, APLP-1 may be cleaved by tripeptide release; however, Notch and CD44 do not fit this processing model $[40,41] . \gamma$-Secretase is widely believed to be a promiscuous protease; however, the cleavage mechanisms of APP and Notch, at least, seem to be different (Figure 4), which indicates that $\gamma$-secretase distinguishes substrates during proteolysis. Perhaps absence of helix breaker glycine residues in mid-portion of transmembrane domain allows multiple S4 cleavages even after single S3 cleavage in Notch. From this point of view, uncovering the mechanisms underlying $\gamma$-secretase-dependent cleavage offers a basis for new therapeutic approaches that are aimed at substrate-specific $\mathrm{A} \beta$ inhibition.

$\begin{array}{ll}\text { Abbreviations } \\ \text { A } \beta: & \text { Amyloid } \beta \text { protein } \\ \text { AICD: } & \text { APP intracellular domain } \\ \text { APP: } & \text { Amyloid precursor protein } \\ \beta C T F: & \text { Carboxyl terminal fragment of APP } \\ \text { DAPT: } & \text { N-[N-(3,5-difluorophenacetyl)-L-alanyl]- }(S) \text { - } \\ & \text { phenylglycine } t \text {-butylester } \\ \text { FAD: } & \text { Familial Alzheimer's disease } \\ \text { LC-MS/MS: } & \text { Liquid chromatography-tandem mass } \\ & \text { spectrometry } \\ \text { N } \beta: & \text { Notch } \beta \text { peptide } \\ \text { NICD: } & \text { Notch intracellular domain } \\ \text { PS: } & \text { Presenilin. }\end{array}$

\section{Acknowledgments}

The authors thank Nobuto Kakuda for critical comments on this paper. Work in the authors' laboratories is supported in part by the Core Research for Evolutional Science and Technology of JST and by MEXT-Supported Program for the Strategic Research Foundation at Private Universities 20122016.

\section{References}

[1] C. Haass, E. H. Koo, A. Mellon, A. Y. Hung, and D. J. Selkoe, "Targeting of cell-surface $\beta$-amyloid precursor protein to lysosomes: alternative processing into amyloid-bearing fragments," Nature, vol. 357, no. 6378, pp. 500-503, 1992.

[2] M. Citron, D. B. Teplow, and D. J. Selkoe, "Generation of amyloid $\beta$ protein from its precursor is sequence specific," Neuron, vol. 14, no. 3, pp. 661-670, 1995.

[3] R. Vassar, B. D. Bennett, S. Babu-Khan et al., " $\beta$-Secretase cleavage of Alzheimer's amyloid precursor protein by the transmembrane aspartic protease BACE," Science, vol. 286, no. 5440, pp. 735-741, 1999.

[4] I. Pinnix, U. Musunuru, H. Tun et al., "A novel $\gamma$-secretase assay based on detection of the putative C-terminal fragment$\gamma$ of amyloid $\beta$ protein precursor," Journal of Biological Chemistry, vol. 276, no. 1, pp. 481-487, 2001.

[5] D. J. Selkoe, "Alzheimer's disease: genes, proteins, and therapy," Physiological Reviews, vol. 81, no. 2, pp. 741-766, 2001.

[6] B. De Strooper, P. Saftig, K. Craessaerts et al., "Deficiency of presenilin-1 inhibits the normal cleavage of amyloid precursor protein," Nature, vol. 391, no. 6665, pp. 387-390, 1998.

[7] B. De Strooper and G. König, "Alzheimer's disease. A firm base for drug development," Nature, vol. 402, no. 6761, pp. 471472, 1999.

[8] M. S. Wolfe, W. Xia, B. L. Ostaszewski, T. S. Diehl, W. T. Kimberly, and D. J. Selkoe, "Two transmembrane aspartates in presenilin-1 required for presenilin endoproteolysis and $\gamma$ secretase activity," Nature, vol. 398, no. 6727, pp. 513-517, 1999. 
[9] G. Struhl and I. Greenwald, "Presenilin is required for activity and nuclear access of notch in drosophila," Nature, vol. 398, no. 6727 , pp. 522-525, 1999.

[10] G. Yu, M. Nishimura, S. Arawaka et al., "Nicastrin modulates presenilin-mediated notch/glp-1 signal transduction and BAPP processing," Nature, vol. 407, no. 6800, pp. 48-54, 2000.

[11] C. Goutte, "Genetics leads the way to the accomplices of presenilins," Developmental Cell, vol. 3, no. 1, pp. 6-7, 2002.

[12] R. Francis, G. McGrath, J. Zhang et al., "aph-1 and pen-2 are required for Notch pathway signaling, $\gamma$-secretase cleavage of $\beta A P P$, and presenilin protein accumulation," Developmental Cell, vol. 3, no. 1, pp. 85-97, 2002.

[13] D. Edbauer, E. Winkler, J. T. Regula, B. Pesold, H. Steiner, and C. Haass, "Reconstitution of $\gamma$-secretase activity," Nature Cell Biology, vol. 5, no. 5, pp. 486-488, 2003.

[14] W. T. Kimberly, M. J. LaVoie, B. L. Ostaszewski, W. Ye, M. S. Wolfe, and D. J. Selkoe, " $\gamma$-Secretase is a membrane protein complex comprised of presenilin, nicastrin, aph-1, and pen2," Proceedings of the National Academy of Sciences of the United States of America, vol. 100, no. 11, pp. 6382-6387, 2003.

[15] N. Takasugi, T. Tomita, I. Hayashi et al., "The role of presenilin cofactors in the $\gamma$-secratase complex," Nature, vol. 422, no. 6930, pp. 438-441, 2003.

[16] A. J. Beel and C. R. Sanders, "Substrate specificity of $\gamma$ secretase and other intramembrane proteases," Cellular and Molecular Life Sciences, vol. 65, no. 9, pp. 1311-1334, 2008.

[17] M. S. Brown, J. Ye, R. B. Rawson, and J. L. Goldstein, "Regulated intramembrane proteolysis: a control mechanism conserved from bacteria to humans," Cell, vol. 100, no. 4, pp. 391-398, 2000.

[18] M. S. Wolfe and R. Kopan, "Intramembrane proteolysis: theme and variations," Science, vol. 305, no. 5687, pp. 1119 $1123,2004$.

[19] A. Tolia, K. Horré, and B. De Strooper, "Transmembrane domain 9 of presenilin determines the dynamic conformation of the catalytic site of $\gamma$-secretase," Journal of Biological Chemistry, vol. 283, no. 28, pp. 19793-19803, 2008.

[20] S. Takagi, A. Tominaga, C. Sato, T. Tomita, and T. Iwatsubo, "Participation of transmembrane domain 1 of presenilin 1 in the catalytic pore structure of the $\gamma$-secretase," Journal of Neuroscience, vol. 30, no. 47, pp. 15943-15950, 2010.

[21] C. Sato, S. Takagi, T. Tomita, and T. Iwatsubo, "The C-terminal PAL motif and transmembrane domain 9 of presenilin 1 are involved in the formation of the catalytic pore of the $\gamma$ secretase," Journal of Neuroscience, vol. 28, no. 24, pp. 62646271, 2008.

[22] K. Takeo, N. Watanabe, T. Tomita, and T. Iwatsubo, "Contribution of the $\gamma$-secretase subunits to the formation of catalytic pore of presenilin 1 protein," Journal of Biological Chemistry, vol. 287, no. 31, pp. 25834-25843, 2012.

[23] P. Osenkowski, H. Li, W. Ye et al., "Cryoelectron microscopy structure of purified $\gamma$-secretase at $12 \AA$ resolution," Journal of Molecular Biology, vol. 385, no. 2, pp. 642-652, 2009.

[24] M. Citron, T. Oltersdorf, C. Haass et al., "Mutation of the $\beta$-amyloid precursor protein in familial Alzheimer's disease increases $\beta$-protein production," Nature, vol. 360, no. 6405, pp. 672-674, 1992.

[25] J. T. Jarrett, E. P. Berger, and P. T. Lansbury, "The carboxy terminus of the $\beta$ amyloid protein is critical for the seeding of amyloid formation: implications for the pathogenesis of Alzheimer's disease," Biochemistry, vol. 32, no. 18, pp. 46934697, 1993.

[26] R. Wang, D. Sweeney, S. E. Gandy, and S. S. Sisodia, "The profile of soluble amyloid $\beta$ protein in cultured cell media. Detection and quantification of amyloid $\beta$ protein and variants by immunoprecipitation-mass spectrometry," Journal of Biological Chemistry, vol. 271, no. 50, pp. 31894-31902, 1996.

[27] M. Citron, D. Westaway, W. Xia et al., "Mutant presenilins of Alzheimer's disease increase production of 42-residue amyloid $\beta$-protein in both transfected cells and transgenic mice," Nature Medicine, vol. 3, no. 1, pp. 67-72, 1997.

[28] N. J. Clarke, A. J. Tomlinson, Y. Ohyagi, S. Younkin, and S. Naylor, "Detection and quantitation of cellularly derived amyloid $\beta$ peptides by immunoprecipitation-HPLC-MS," FEBS Letters, vol. 430, no. 3, pp. 419-423, 1998.

[29] D. Beher, J. D. J. Wrigley, A. P. Owens, and M. S. Shearman, "Generation of C-terminally truncated amyloid- $\beta$ peptides is dependent on $\gamma$-secretase activity," Journal of Neurochemistry, vol. 82, no. 3, pp. 563-575, 2002.

[30] Y. Gu, H. Misonou, T. Sato, N. Dohmae, K. Takio, and Y. Ihara, "Distinct intramembrane cleavage of the beta-amyloid precursor protein family resembling gamma-secretase-like cleavage of Notch," Journal of Biological Chemistry, vol. 276, no. 38, pp. 35235-35238, 2001.

[31] M. Sastre, H. Steiner, K. Fuchs et al., "Presenilin-dependent $\gamma$ secretase processing of $\beta$-amyloid precursor protein at a site corresponding to the S3 cleavage of Notch," EMBO Reports, vol. 2, no. 9, pp. 835-841, 2001.

[32] A. Weidemann, S. Eggert, F. B. M. Reinhard et al., "A novel $\varepsilon$-cleavage within the transmembrane domain of the Alzheimer amyloid precursor protein demonstrates homology with notch processing," Biochemistry, vol. 41, no. 8, pp. 28252835, 2002.

[33] I. Okamoto, Y. Kawano, D. Murakami et al., "Proteolytic release of CD44 intracellular domain and its role in the CD44 signaling pathway," Journal of Cell Biology, vol. 155, no. 5, pp. 755-762, 2001.

[34] H. J. Lee, K. M. Jung, Y. Z. Huang et al., "Presenilin-dependent $\gamma$-secretase-like intramembrane cleavage of ErbB4," Journal of Biological Chemistry, vol. 277, no. 8, pp. 6318-6323, 2002.

[35] P. Marambaud, J. Shioi, G. Serban et al., "A presenilin- $1 / \gamma$ secretase cleavage releases the E-cadherin intracellular domain and regulates disassembly of adherens junctions," $E M B O$ Journal, vol. 21, no. 8, pp. 1948-1956, 2002.

[36] P. May, Y. Krishna Reddy, and J. Herz, "Proteolytic processing of low density lipoprotein receptor-related protein mediates regulated release of its intracellular domain," Journal of Biological Chemistry, vol. 277, no. 21, pp. 18736-18743, 2002.

[37] T. Ikeuchi and S. S. Sisodia, "The Notch ligands, Delta1 and Jagged2, are substrates for presenilin-dependent " $\gamma$-secretase" cleavage," Journal of Biological Chemistry, vol. 278, no. 10, pp. 7751-7754, 2003.

[38] M. Takami, Y. Nagashima, Y. Sano et al., " $\gamma$-Secretase: successive tripeptide and tetrapeptide release from the transmembrane domain of $\beta$-carboxyl terminal fragment," Journal of Neuroscience, vol. 29, no. 41, pp. 13042-13052, 2009.

[39] K. Yanagida, M. Okochi, S. Tagami et al., "The 28-amino acid form of an APLPl-derived A $\beta$-like peptide is a surrogate marker for A $\beta 42$ production in the central nervous system," EMBO Molecular Medicine, vol. 1, no. 4, pp. 223-235, 2009.

[40] J. Wanngren, J. Ottervald, S. Parpal et al., "Second generation $\gamma$-secretase modulators exhibit different modulation of notch $\beta$ and $\mathrm{A} \beta$ production," Journal of Biological Chemistry, vol. 287, no. 39, pp. 32640-32650, 2012.

[41] S. Lammich, M. Okochi, M. Takeda et al., "Presenilindependent intramembrane proteolysis of CD44 leads to the liberation of its intracellular domain and the secretion of an 
A $\beta$-like peptide," Journal of Biological Chemistry, vol. 277, no. 47, pp. 44754-44759, 2002.

[42] T. Sato, N. Dohmae, Y. Qi et al., "Potential link between amyloid beta-protein 42 and C-terminal fragment gamma 4999 of beta-amyloid precursor protein," Journal of Biological Chemistry, vol. 278, no. 27, pp. 24294-20301, 2003.

[43] S. Funamoto, M. Morishima-Kawashima, Y. Tanimura, N. Hirotani, T. C. Saido, and Y. Ihara, "Truncated carboxylterminal fragments of $\beta$-amyloid precursor protein are processed to amyloid $\beta$-proteins 40 and 42," Biochemistry, vol. 43, no. 42, pp. 13532-13540, 2004.

[44] Y. Qi-Takahara, M. Morishima-Kawashima, Y. Tanimura et al., "Longer forms of amyloid $\beta$ protein: implications for the mechanism of intramembrane cleavage by $\gamma$-secretase," Journal of Neuroscience, vol. 25, no. 2, pp. 436-445, 2005.

[45] L. Chévez-Gutiérrez, L. Bammens, I. Benilova et al., "The mechanism of $\gamma$-Secretase dysfunction in familial Alzheimer disease," EMBO Journal, vol. 31, no. 10, pp. 2261-2274, 2012.

[46] O. Quintero-Monzon, M. M. Martin, M. A. Fernandez, C. A. Cappello, P. Osenkowski, and M. S. Wolfe, "Dissociation between the processivity and total activity of $\gamma$-secretase: implications for the mechanism of Alzheimer's diseasecausing presenilin mutations," Biochemistry, vol. 50, no. 42, pp. 9023-9035, 2011.

[47] H. F. Dovey, V. John, J. P. Anderson et al., "Functional gammasecretase inhibitors reduce beta-amyloid peptide levels in brain," Journal of Neurochemistry, vol. 76, no. 1, pp. 173-181, 2001.

[48] G. Zhao, G. Mao, J. Tan et al., "Identification of a new presenilin-dependent $\zeta$-cleavage site within the transmembrane domain of amyloid precursor protein," Journal of Biological Chemistry, vol. 279, no. 49, pp. 50647-50650, 2004.

[49] G. Zhao, M. Z. Cui, G. Mao et al., " $\gamma$-cleavage is dependent on $\zeta$-cleavage during the proteolytic processing of amyloid precursor protein within its transmembrane domain," Journal of Biological Chemistry, vol. 280, no. 45, pp. 37689-37697, 2005.

[50] T. Sato, Y. Tanimura, N. Hirotani, T. C. Saido, M. MorishimaKawashima, and Y. Ihara, "Blocking the cleavage at midportion between $\gamma$ - and $\varepsilon$-sites remarkably suppresses the generation of amyloid $\beta$-protein," FEBS Letters, vol. 579, no. 13, pp. 2907-2912, 2005.

[51] K. S. Vetrivel, H. Cheng, W. Lin et al., "Association of $\gamma$-secretase with lipid rafts in post-golgi and endosome membranes," Journal of Biological Chemistry, vol. 279, no. 43, pp. 44945-44954, 2004.

[52] S. Yagishita, M. Morishima-Kawashima, S. Ishiura, and Y. Ihara, "A $\beta 46$ is processed to $\mathrm{A} \beta 40$ and $\mathrm{A} \beta 43$, but not to $\mathrm{A} \beta 42$, in the low density membrane domains," Journal of Biological Chemistry, vol. 283, no. 2, pp. 733-738, 2008.

[53] S. Yagishita, M. Morishima-Kawashima, Y. Tanimura, S. Ishiura, and Y. Ihara, "DAPT-induced intracellular accumulations of longer amyloid $\beta$-proteins: further implications for the mechanism of intramembrane cleavage by $\gamma$-secretase," Biochemistry, vol. 45, no. 12, pp. 3952-3960, 2006.

[54] A. Fukumori, R. Fluhrer, H. Steiner, and C. Haass, "Threeamino acid spacing of presenilin endoproteolysis suggests a general stepwise cleavage of $\gamma$-secretase-mediated intramembrane proteolysis," Journal of Neuroscience, vol. 30, no. 23, pp. 7853-7862, 2010.

[55] S. Osawa, S. Funamoto, M. Nobuhara et al., "Phosphoinositides suppress $\gamma$-secretase in both the detergent-soluble and -insoluble states," Journal of Biological Chemistry, vol. 283, no. 28, pp. 19283-19292, 2008.
[56] M. Okochi, H. Steiner, A. Fukumori et al., "Presenilins mediate a dual intramembranous $\gamma$-secretase cleavage of Notch-1," EMBO Journal, vol. 21, no. 20, pp. 5408-5416, 2002.

[57] M. Okochi, A. Fukumori, J. Jiang et al., "Secretion of the Notch-1 A $\beta$-like peptide during Notch signaling," Journal of Biological Chemistry, vol. 281, no. 12, pp. 7890-7898, 2006. 


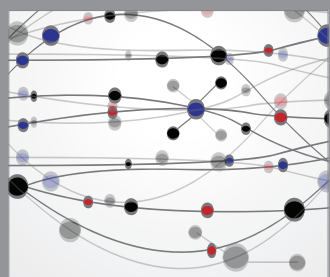

The Scientific World Journal
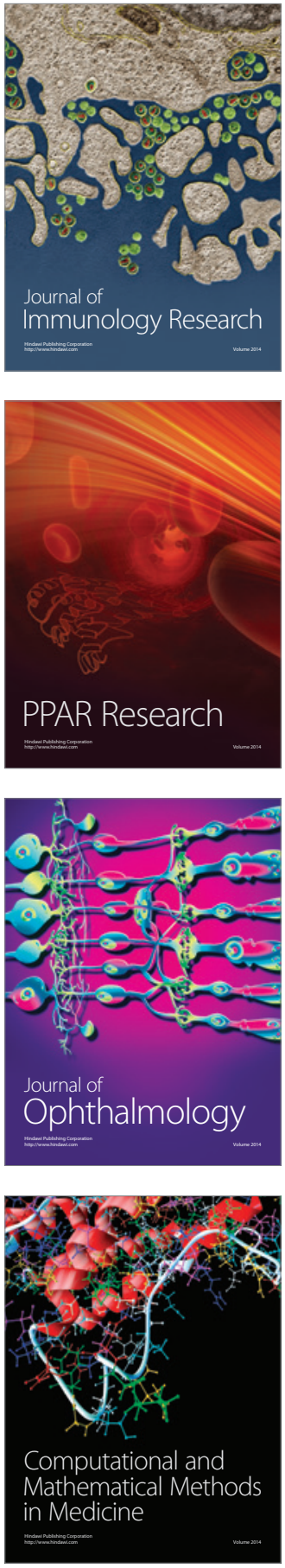

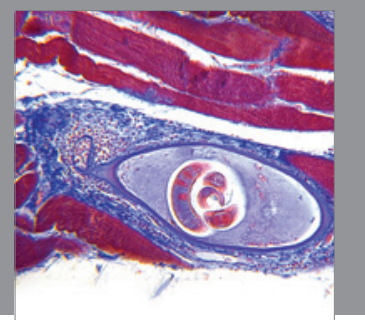

Gastroenterology

Research and Practice
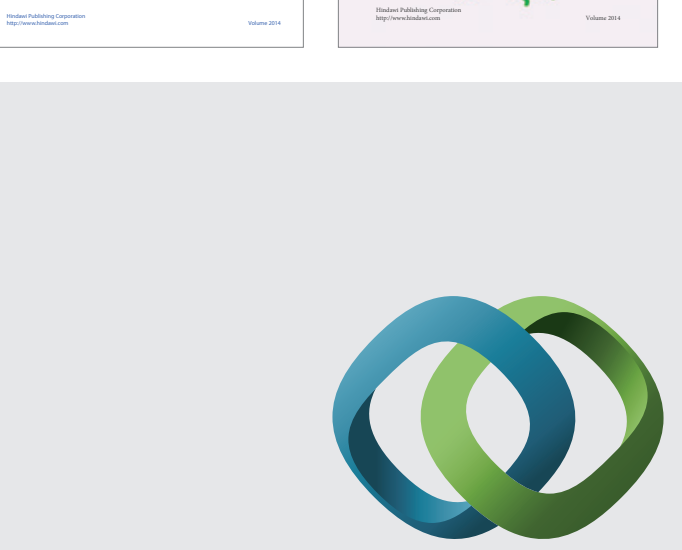

\section{Hindawi}

Submit your manuscripts at

http://www.hindawi.com
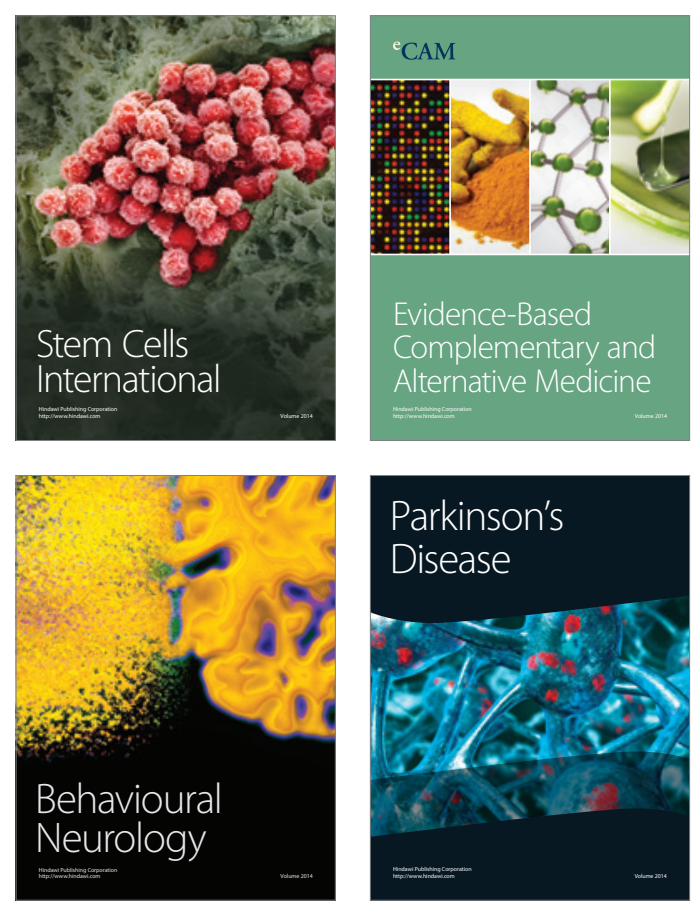

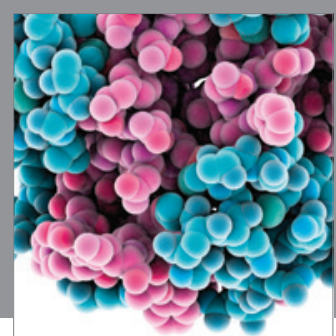

Journal of
Diabetes Research

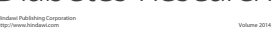

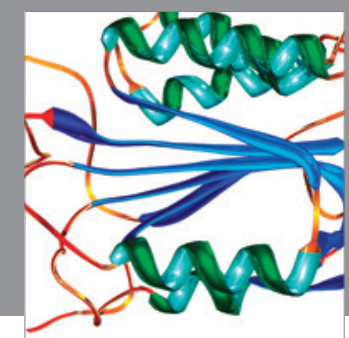

Disease Markers
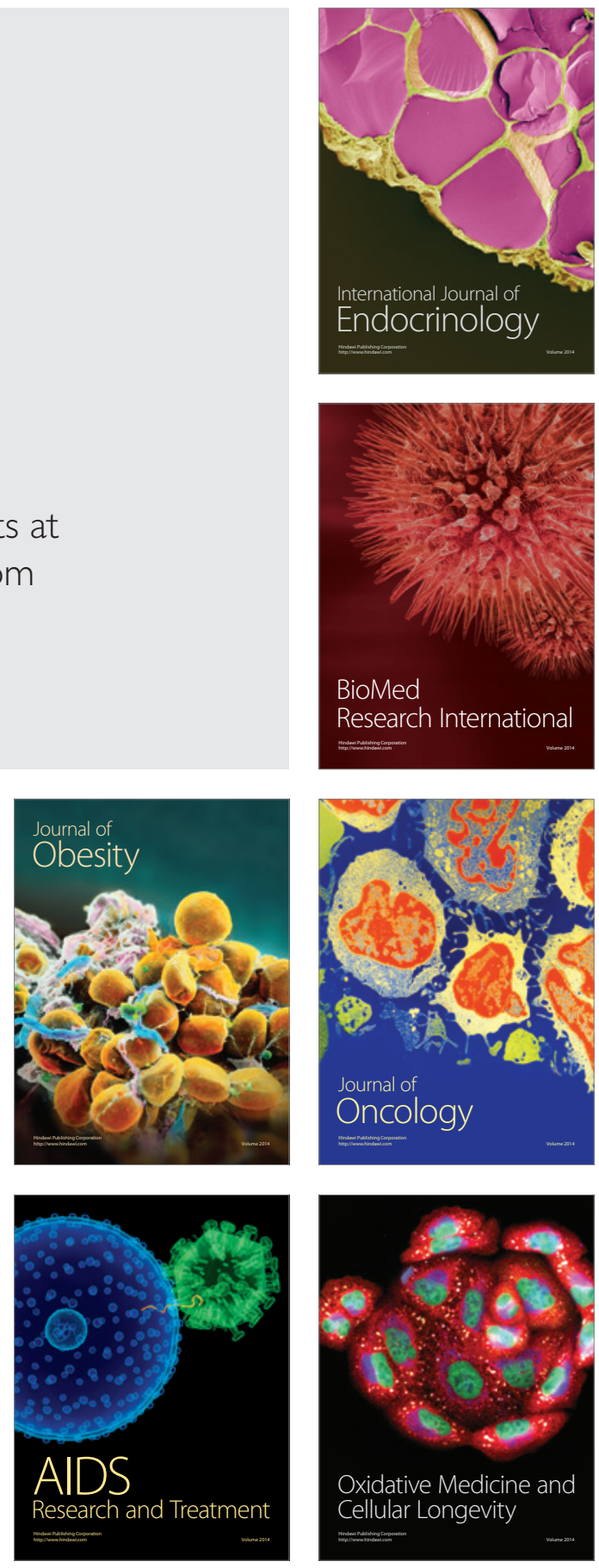